\section{$\underset{\text { hommes }}{\text { \& migrations }}$}

\section{Hommes \& migrations}

Revue française de référence sur les dynamiques

migratoires

$1312 \mid 2015$

Diasporas iraniennes

\title{
Emondo De Amincis, Souvenirs de Paris
}

Edition d'Alberto Brambilla et Aurélie Gendrat-Claudel, Rue d'Ulm, 2015, 200 pages, $16 €$

\section{Mustapha Harzoune}

\section{OpenEdition}

\section{Journals}

Édition électronique

URL : http://journals.openedition.org/hommesmigrations/3544

DOI : 10.4000/hommesmigrations.3544

ISSN : 2262-3353

Éditeur

Musée national de l'histoire de l'immigration

Édition imprimée

Date de publication : 1 octobre 2015

Pagination : 158-159

ISBN : 978-2-919040-33-9

ISSN : $1142-852 X$

Référence électronique

Mustapha Harzoune, "Emondo De Amincis, Souvenirs de Paris », Hommes \& migrations [En ligne],

1312 | 2015, mis en ligne le 31 mai 2016, consulté le 24 septembre 2020. URL : http://

journals.openedition.org/hommesmigrations/3544 ; DOI : https://doi.org/10.4000/

hommesmigrations.3544 


\section{LIVRES}

Abi est son fidèle Délégué". L’abilang, la langue "nationale exclusive omnipotente", y est sacralisée, divinisée. Elle a remplacé la langue d'avant, "une langue très belle, riche, suggestive... comme elle inclinait à la poésie et à la rhétorique, elle a été effacée de l'Abistan, on lui a préféré l'abilang, il force au devoir et à la stricte l'obéissance". C'est par une longue et patiente description de cette organisation, la mécanique du pouvoir, l'enchevêtrement des instances de contrôle, la multiplicité des dispositifs sécuritaires, que s'ouvre le roman. Trois grains de sable - les universelles liberté, vérité et poésie -, incarnés par Ati, Nas, et Koa, enrayeront - peut-être - la mécanique trop bien huilée. 2084 est tout cela. Et plus encore.

Le roman invite aussi, explicitement, à réfléchir, à "déconstruire", ce qui structure nos cadres conceptuels et nos imaginaires depuis au moins le XIX ${ }^{e}$ siècle, à commencer par les notions de peuple, d'identité ou de frontière. Il est difficile de ne pas lire 2084 sans penser à ce qui fait

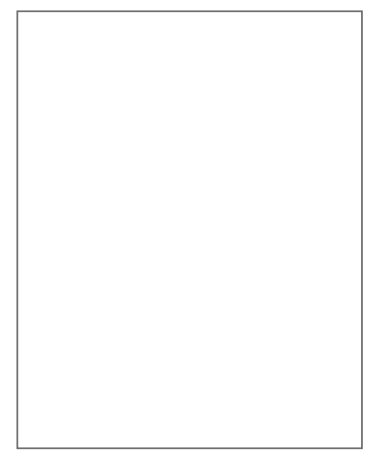

Edmondo

De Amicis

Souvenirs

de Paris

édition d'Alberto Brambilla et Aurélie Gendrat-Claudel, Rue d'Ulm, 2015, 200 pages, $16 €$

Écrivain italien, journaliste et reporter, Edmon-

do De Amicis s'en vient, en juin 1878 , à Paris visiter l'Exposition universelle. notre longue actualité et à ses retombées médiatiques et politiques: l'instrumentalisation des peurs; l'avancée des ignorances ; le mensonge fait argument ; les ressorts de la soumission ; les réductions et les raccourcis imposés par une autre novlangue, celle des médias, des réseaux sociaux et des estrades; les logiques binaires et la production de boucs émissaires ; le retour distinctif et exclusif du Je et de l'Autre qui construit l'image mentale de peuples désindividualisés, essentialisés...

Si 2084 dénonce avec force l'islamisation, il met aussi en garde les démocraties contre les pourrissements en cours. Nous serions tous dans le même bain : Sud ET Nord, Occident ET Orient, religieux ET laïcs, croyants ET athées... Véhiculant les mêmes peurs, supportant les mêmes détresses, portant les mêmes impasses. De ce point de vue, 2084 est aussi une invitation à dépasser la frontière. Comme Ati à la fin de ce roman, qui est d'abord et avant tout le roman d'un grand écrivain. $M$. H.

Cela sera l'occasion d'expédier à son journal une série d'articles sur la manifestation et sur la ville. Regard italien, enthousiaste et malicieux, admiratif et critique sur la capitale française, celle des beaux quartiers et des mondains et sur ces Parisiens de la seconde moitié du XIXe siècle.

En 1879, ces articles sont rassemblés sous le titre Ricordi di Parigi, souvenirs ici édités, commentés en postface par Alberto Brambilla (Paris-Sorbonne) et Aurélie Gendrat-Claudel (maître de 
conférences à Paris-Sorbonne) et mis en perspective biographique, littéraire, épistolaire, grâce à la correspondance parisienne de l'auteur.

"On ne voit jamais Paris pour la première fois, on le revoit", écrit Edmondo De Amicis, qui retrouve les lieux et les personnages des romans et des romanciers qu'il a lus et admire, à commencer par Zola qu'il visitera et qui lui déclarera son amour pour le pays de son père. Débarqué à la gare de Lyon, il va par la Bastille, les boulevards Beaumarchais et du Temple, puis les Grands Boulevards en direction de la Madeleine et de la Concorde. À Notre-Dame, il grimpe à l'une des tours: "Il faut au moins les dominer, ces villes monstrueuses, de la seule façon par nous possible, du regard." C'est de loin et haut perché qu'il distingue les "faubourgs énormes, entassés sur les hauteurs, comme des bataillons prêts à descendre, pleins de tristesses et de menaces".

Au ras des pavés, le voyageur se noie dans l'immensité et le tourbillon de la ville. La foule y est disparate, diverse, le cosmopolisme est pour l'heure tout occidental. Les chaussées sont déjà encombrées - on n'ose parler d'embouteillages -, et les "réclames" envahissantes au point que "le ciel lui-même n'est pas libre" et "qu'en marchant une heure, on lit, à son corps défendant, un demi-volume". Paris fourmille, se bouscule, frémit, "ce n'est qu'un va-et-vient". Et à l'heure où la lumière du jour baisse, "la nuit de Paris, chargée de folies et de péchés, prépare ses célèbres embûches". Le Parisien goûte les plaisirs, la "légèreté", "la blague", le champagne : "Alors avec quel élan nous saluons le grand
Paris, l'hôte aimable et généreux qui à tous ouvre ses bras et distribue en riant les baisers, l'or et les idées, et ravive dans tous les coeurs, avec son souffle juvénile, le désir de la gloire et l'amour de la vie !" Mais, après "la lune de miel", "le moment arrive où la ville devient antipathique". De Amicis écrit alors au lance-flammes ! Le style flamboyant mêle le vitriol à la drôlerie. L'observation y est fine et à la loupe. Les avis, près de cent quarante ans plus tard, ne manquent pas de pertinence. Tout y passe. Le sourire de la propriétaire, la vanité des concierges, l'impertinence des serveurs de café, la grossièreté des cochers... Les plaisirs sont devenus les vices d'une "ville dévergondée". Tout n'est que saletés et laideurs! Femmes et hommes mêlés. L'Italien raille cette démocratie où le prestige du pouvoir reste intact, où percent les relents aristocratiques de l'Ancien Régime, où les citoyens sont des moutons de Panurge. Ici, les littérateurs ne sont pas les derniers: "Où a-t-on vu une littérature plus amoureuse du blason, des écrivains qui salivent avec tant de candeur au son d'un titre de noblesse (...)" ? "La vanité les empeste tous". Les manies de faire de l'esprit finissent par "châtrer la pensée" dans ce Paris où "tout est dominé et gâté par la manie de la pose". C'est dit!

Après avoir "vidé son sac", notre Italien revient à de meilleurs sentiments car "Paris lui-même vous offre mille échappatoires à ses dangers et mille remèdes à ses fièvres". Indulgent aussi, car il faut "vous mettre à la place d'un peuple qui se voit singé par tout l'univers".

M. H. 